\title{
Materiais didáticos digitais interativos para tablets e interação em sala de aula
}

\section{Jezreel Gabriel Lopes}

Universidade Estadual de Campinas (Unicamp)

\begin{abstract}
Resumo
Este artigo tem por objetivo analisar, por meio de pesquisa de observação participante, uma experiência de uso de material didático digital interativo (MDDI) para tablets a fim de verificar como se realizam os processos de produção e condução da prática docente nessas condições.

Palavras-chave: Material didático digital interativo, multiletramentos, interação em sala de aula.
\end{abstract}

\begin{abstract}
The objective of this article is to analyze, through participant observation research, the processes and conduct of teaching practice mediated by digital interactive courseware (DIC) for tablets.

Keywords: Digital interactive courseware, multiliteracies, classroom interaction
\end{abstract}

\section{MULTILETRAMENTOS E NOVOS LETRAMENTOS}

Diante do contexto de evolução tecnológica e de estabelecimento de novas relações e práticas sociais, em meados da década de noventa, um grupo de especialistas em linguagem e educação, conhecido como Grupo de Nova Londres (2006[2000]), articulou o conceito de multiletramentos a partir da observação e interpretação das mudanças vigentes no mundo naquela época e ainda hoje. O termo multiletramentos foi cunhado de forma a ser capaz de designar dois tipos de multiplicidade crescentes na sociedade, a multissemiose dos textos em circulação e a multiplicidade de culturas em contato no mundo globalizado.

Sobre a primeira das multiplicidades discutidas pelo Grupo de Nova Londres (a multimodalidade ou multissemiose), pode-se dizer que a contemporaneidade apresenta um contexto comunicacional no qual a informação, por meio de variadas 
mídias ${ }^{\mathrm{i}}$, materializa-se em diversas modalidades de linguagem ${ }^{\text {ii }}$ que se combinam entre si durante o processo comunicativo, expandindo ou limitando a significação de um determinado discurso (LEMKE, 2011).

Além da multissemiose, como afirmado anteriormente, o conceito de multiletramentos também se relaciona à multiplicidade de culturas, expressas por diferentes linguagens e seus usos em contextos específicos. Assim, Cope e Kalantzis (2006, p. 166) explicam que, central à abordagem por eles proposta, está a crescente variedade de "linguagens sociais" iii, nomenclatura proposta por Gee (1996), em grupos de interesse ou afinidade no âmbito profissional, nacional, étnico e subcultural. Segundo os autores, a disseminação dessas multiplicidades (culturais, de linguagens) acompanha a reestruturação do funcionamento de três âmbitos da vida humana: o do trabalho (diversidade produtiva), o da cidadania (pluralismo cívico) e o da vida social (KALANTZIS; COPE, 2006). Para Cope e Kalantzis, dessa forma, além de considerar as multiplicidades abarcadas pelos multiletramentos, uma educação linguística apropriada ao contexto contemporâneo precisa levar em conta a reestruturação desses âmbitos da vida humana e suas demandas.

Embora o contexto contemporâneo tecnológico e multicultural esteja na base da definição do conceito de multiletramentos proposto pelo Grupo de Nova Londres, é um equívoco considerá-lo como sinônimo do conceito de novos letramentos proposto por Lankshear e Knobel (2007). Enquanto o primeiro constrói-se com base na multissemiose e multiculturalidade, o segundo, ainda que eventualmente acabe por abarcar esses dois aspectos, necessita das perspectivas técnicas oriundas das novas tecnologias de informação e comunicação juntamente a uma nova ética proporcionada por essas tecnologias. Assim, é possível afirmar que nem toda prática social situada nos multiletramentos é, de fato, um novo letramento.

Em resposta à questão acerca do que então constitui um novo letramento, Lankshear e Knobel (2007) afirmam que "novos letramentos têm o que se denomina de new technical stuff e new ethos stuff" (p.7) ${ }^{\text {iv }}$. Segundo Lankshear e Knobel, para conceituar o que chama de new technical stuff, é preciso considerar que há atualmente

\footnotetext{
${ }^{\text {i } M i d i a, ~ d e ~ a c o r d o ~ c o m ~ a ~ d e f i n i c ̧ a ̃ o ~ d e ~ K r e s s ~(2005), ~ e ́ ~ u m ~ m e i o ~ d e ~ c i r c u l a c ̧ a ̃ o ~ d e ~ m e n s a g e n s ~}$ culturalmente significativas.

ii Ainda segundo Kress (2005), modalidade é um meio de representação baseado em uma materialidade específica, compartilhado social e culturalmente.

iii Gee faz uso do mesmo termo utilizado por Bakhtin (1985[1934-35/1975]).

iv (...) new literacies have what we call new "technical stuff” and new "ethos stuff".
} 
à disposição diferentes tipos de aparatos tecnológicos, como computadores, consoles de games, mp3 players, por meio dos quais se utilizam softwares com aplicabilidades diversas, como, por exemplo, produção e edição de textos, de animação e para comunicação. Para os autores, um novo ethos consiste em uma nova ética, uma nova realidade para lidar com os discursos veiculados na sociedade contemporânea. Essa nova ética enfatiza uma maior participação das pessoas e maior colaboratividade na produção de discursos, fator que resulta na dissolução da autoria e em relações assimétricas. Além disso, dispensam-se conhecimentos técnicos altamente especializados e recursos tecnológicos caros na produção de tais discursos, fato que, há algumas décadas, não seria possível. Consequentemente, evidencia-se que nesse novo ethos as regras e normas são mais fluídas e menos formatadas.

Com base nos conceitos de multi e novos letramentos, procuramos estruturar o material didático digital interativo utilizado para este estudo.

\section{SISTEMA DE ATIVIDADES E DE GÊNEROS}

Bazerman (2004) define o conjunto de gêneros como a coleção de gêneros que uma pessoa tende a produzir num determinado papel. O sistema de gêneros, segundo o autor, compreende os diversos conjuntos de gêneros utilizados por pessoas que trabalham juntas de uma forma organizada, além das relações padronizadas que se estabelecem na produção, circulação e uso dos textos. Por meio de um sistema de gêneros é possível capturar as sequências regulares com que um gênero segue outro gênero, dentro de um fluxo comunicativo típico de um grupo de indivíduos.

Bazerman explica que o sistema de gêneros pode constituir também uma parte do sistema de atividades da sala de aula. Segundo ele, ao definir o sistema de gêneros em que as pessoas estão envolvidas, é possível identificar as estruturas que organizam seu trabalho.

Rojo (2007) analisou uma aula de história utilizando a ferramenta sinopse, proposta por Schneuwly, Cordeiro \& Dolz (2005), ligeiramente modificada ao incorporar os conceitos de Batista (1997) de sequências globais e locais a fim de definir os níveis hierárquicos das sequências de atividades. A sinopse tem como função observar como os objetos de ensino são abordados no decorrer de uma aula, estabelecendo, assim, uma sequencialidade hierárquica das atividades didáticas. Rojo (2007), em seu estudo, considerou a sequencialidade hierárquica da aula observada como um sistema de atividades e analisou os sistemas de gêneros, fazendo referência 
ao conceito proposto por Bazerman (2004), que organizam os textos que na aula circulam.

Assim, para a análise posterior da estrutura da aula mediada por MDDI, adotaremos o conceito de estruturação da aula como sistema de atividades e de gêneros de Rojo (2007), embasada em Bazerman (2004).

\section{AS INSTÂNCIAS DISCURSIVAS DA AULA}

A partir de uma perspectiva mais enunciativa e menos etnográfica e sociolinguística, ao longo das observações de aula que serviram de base para sua pesquisa, Batista (1997) conclui que "o uso da linguagem na aula originava um conjunto diversificado de textos, produzidos e utilizados em diferentes condições enunciativas" (p. 32). Segundo o autor, tais textos eram heterogêneos e dispersos, mas, de algum modo, eram articulados e homogeneizados. A análise para determinar "os mecanismos que asseguravam àquele conjunto heterogêneo e disperso de textos a possibilidade de se articular e de seguir construindo uma progressão discursiva" revelou que a produção discursiva se organizava em duas instâncias - a instância da aula e a instância do exercício —, que ofereciam "diferentes e relacionadas condições de produção de discurso, isto é, diferentes e relacionadas modalidades de enunciação, objetivos e estratégias discursivas” (p. 33). Embora apresentem diferentes aspectos, Batista salienta que as duas instâncias "mantêm entre si relações de constituição" e que "sua alternância possibilita a interlocução em sala de aula, assim como sua continuidade" (p. 34).

A interlocução que se realiza oralmente entre professor e turma em sala de aula é aquela produzida sob orientações e condições da instância da aula. Por meio da análise de tal interlocução, de acordo com o Batista (1997), é possível depreender três conjuntos de estratégias discursivas que se realizam na instância em questão: "aquelas por meio das quais se faz a organização local e intermediária do discurso, aquelas por meio das quais se constituem os polos da interlocução e aquelas por meio das quais se faz a organização global da interlocução" (p. 39).

Por meio do primeiro conjunto de estratégias, organiza-se localmente o discurso, ou seja, organizam-se as unidades menores desse discurso com base em sequências triádicas de turnos, em que "a fala do aluno se encontra controlada e envolvida pelos turnos de pergunta e reação do professor” (p. 41). Para ilustrar tal constatação, Batista descreve o momento de correção de um estudo de texto feito por 
uma professora e sua turma. A cada questão corrigida, a interlocução materializava-se por meio de sequências triádicas e, assim que a professora satisfazia-se com a resposta dada por seus alunos, ela abandonava a pergunta em que vinha se baseando e propunha uma nova questão. O pesquisador aponta que "organiza-se, assim, também, a interlocução num nível intermediário. Um conjunto de sequências triádicas em torno de uma mesma pergunta retirada dos exercícios ou de atividades feitas anteriormente formam uma unidade hierarquicamente superior. É, assim, através desses processos que progride, de forma organizada, o discurso em sala de aula" (p. 42).

O segundo conjunto de estratégias, aquelas que visam a constituição de polos de interlocução, realiza-se com frequência por meio de atos de fala de repreensão, cujo objetivo é reduzir a possibilidade de interações em sala de aula, de forma a constituir um corpo unificado de alunos centrado pela atenção na figura do professor.

Batista aponta que se constituem, assim, os polos da interlocução e marcam-se os papéis daqueles que o ocupam: "o reconhecimento tácito da autoridade do professor, promovido pela estratégia, implica ainda, o reconhecimento tácito da posse, por ele, da dominância da interlocução, e o reconhecimento, também tácito, do papel dominado dos alunos nessa interlocução" (p. 54).

Por fim, Batista explica que as estratégias que organizam globalmente a interlocução, ou seja, a organização global da interlocução, agem através de dois mecanismos distintos. O primeiro deles, aplicado quando o objeto de ensino é gramatical, constitui-se no desenvolvimento, por meio de análise, de um objeto de ensino gramatical e a retomada, por meio da síntese da interlocução anterior. $O$ pesquisador explica que esse mecanismo organiza a interlocução "como um conjunto de sequência de atividades relacionadas numa cadeia de discurso que progride temporalmente de tal modo que seus momentos ulteriores contêm parte dos anteriores, acumulados pelo contínuo movimento de recuo e avanço, de síntese e de análise" (p. 67).

Por meio do aparato teórico fornecido por Batista, pretendemos verificar como se estabelecem as relações na instância da aula, no contexto de aula mediada por MDDI. 


\title{
MÉTODOS DE PESQUISA
}

Foi elaborado pelo professor-pesquisador um material didático digital interativo (MDDI) para tablets para o trabalho com leitura e produção de textos no Ensino Médio, a fim de verificar como se dá a interação entre professor-aluno e alunos-MDDI. Foram ministradas e documentadas, também pelo pesquisadorprofessor, duas aulas, com duração de 50 minutos cada, em uma turma de $2^{\circ}$ ano de Ensino Médio de uma escola privada em na região de Campinas - SP, nas quais foi utilizado o MDDI.

$\mathrm{O} \mathrm{MDDI}^{\mathrm{v}}$ preparado para esta pesquisa visa ao ensino-aprendizagem focado em gêneros nas aulas de Língua Portuguesa. Adotamos a concepção de gêneros de discurso proposta por Bakhtin (2003[1952-53/1979]) como "tipos relativamente estáveis de enunciados", elaborados em uma esfera social, caracterizados por seu tema, estilo e construção formal, grandemente ditados pela valoração que os orienta.

Esse material didático foi elaborado por meio do aplicativo IBooks Author, distribuído gratuitamente pela MacApp Store ${ }^{\mathrm{vi}}$. O aplicativo em questão permite que se idealizem livros digitais interativos multimodais, maximizando as possibilidades de uso de dispositivos digitais móveis como os tablets em sala de aula.

Para concepção do MDDI, fizemos uso do conceito de protótipo articulado por Rojo (2013) no qual

\begin{abstract}
Um protótipo de ensino seria um "esqueleto" de SD a ser "encarnado" ou preenchido pelo professor, por exemplo, um modelo didático digital de um gênero ou conjunto de gêneros, sem seus acervos ou bancos de textos, ou apenas com acervos e bancos que funcionassem como exemplos e pudessem ser substituídos no produto final. (ROJO, 2013, p. 189)
\end{abstract}

Se o protótipo é na verdade um esqueleto, o que então o constituiria? Segundo a autora

Justamente o modelo didático do(s) gênero(s) em questão, ou parte dele: aquela parte que diz respeito às características e funcionamento do(s)

\footnotetext{
${ }^{\mathrm{v}}$ Ver Material completo no Anexo 1 deste trabalho.

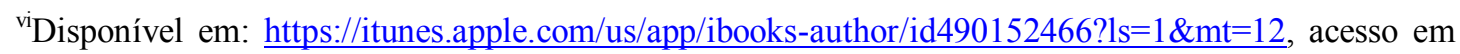
$10 / 10 / 2012$.
} 
gênero(s), segundo as teorias e os saberes práticos correntes, ao conjunto de princípios de ensino-aprendizagem adotados e aos possíveis objetivos de ensino a serem selecionados para compor os módulos de ensino. (ROJO, 2013, p. 190)

Assim, para este estudo, criou-se um protótipo por meio do software Ibooks Author, ou seja, a estrutura do MDDI, e elegeu-se como tema os consensos e controvérsias a respeito do aquecimento global. Tanto a primeira parte do material quanto a segunda são compostas por acervos de textos (reportagens, notícias, artigos de opinião e artigo de divulgação científica), infográficos, imagens, galerias de charges, vídeos e exercícios dissertativos que envolvem a interpretação de textos em gêneros em modalidades diversas (texto escrito, imagem e vídeo) e sua relação uns com os outros. A diferença entre as partes reside na temática. A primeira metade do material didático sustenta a veracidade do aquecimento global enquanto a segunda desconstrói tal verdade. A seção final do MDDI é dedicada à produção de textos em gêneros como dissertação, carta de leitor e postagem no Tumblr, embasada nas discussões previamente realizadas.

A partir da investigação da aula registrada em vídeo, buscamos analisar a estruturação da aula aplicada como um sistema de atividade e gêneros com base em Bazerman (2004) e Rojo (2007). Além disso, analisamos se os aspectos referentes à interlocução estabelecida em sala de aula e às interações nas instâncias da aula (professor-alunos) e na instância do exercício (alunos-material didático) presentes na aula intermediada por MDDI e tablets são os mesmos que as verificadas por Batista (1997) em uma aula tradicional.

\section{A ESTRUTURAÇÃO DA AULA MEDIANTE O USO DE MDDI}

O material digital interativo foi criado para a disciplina de Produção e Interpretação Textual. Sua concepção visava o trabalho com multiletramentos e novos letramentos a partir de materiais de divulgação científica. Ele foi pensado para contrapor discursos científicos contrastantes acerca de um mesmo assunto por meio de leitura e interpretação de gêneros escritos e multissemióticos. Para isso, elegeu-se como temática o fenômeno do aquecimento global. Ao longo de três seções distintas, o MDDI caracteriza o fenômeno e amplia a discussão para questões como o papel dos veículos de comunicação na construção do discurso científico e a influência de fatores políticos, ideológicos e econômicos nesse discurso. Por fim, o material apresenta três sugestões de produção textual. É possível sistematizar os objetivos pedagógicos gerais 
do MDDI da seguinte forma: (a) compreender o fenômeno do aquecimento global e as variáveis que o envolvem; (b) analisar por meio desse fenômeno temáticas de espectro mais amplo, tais como a neutralidade científica e o papel da mídia na divulgação científica; (c) ler, analisar e interpretar gêneros escritos e multissemióticos. Para que se alcance os objetivos gerais, cada uma das partes da seção apresenta objetivos pedagógicos específicos.

Nas tabelas a seguir, encontra-se a descrição de todo o material quanto a seus objetivos, gêneros que o compõem, sistema semiótico em que esses gêneros se enquadram e as modalidades de linguagem presentes. Nele, há especificações quanto aos títulos dos gêneros presentes no material para orientar análises posteriores.

\begin{tabular}{|c|c|c|c|c|c|}
\hline \multirow{6}{*}{ 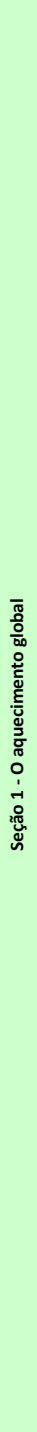 } & Parte da Seção & Objetivos pedagógicos & \begin{tabular}{|c|} 
Gêneros que compõem a parte da \\
seção
\end{tabular} & Sistema semiótico & Modalidades \\
\hline & Fatos do aquecimento & $\begin{array}{l}\text { 1. Contextualizar o aquecimento global, definindo- } \\
\text { o, analisando suas causas, consequências presentes } \\
\text { e futuras; } \\
\text { 2. Identificar recursos linguísticos e demais recursos } \\
\text { em outras semioses, tais como diagramação, } \\
\text { escolha de imagens e cores (em infográficos e } \\
\text { charges), que constroem o caráter de verdade } \\
\text { incontestável das informações apresentadas pelos } \\
\text { gêneros que compoem a parte da seção; } \\
\text { 3. Analisar e interpretar uma reportagem; } \\
\text { 4.Analisar e interpretar infográficos; } \\
\text { 5. Analisar e interpretar charges; } \\
\text { 6. Analisar os efeitos de sentido construídos pelas } \\
\text { imagens ilustrativas da parte da seção. }\end{array}$ & $\begin{array}{l}\text { *Animação curtametragem } \\
\text { (vídeo introdutório); } \\
\text { * Reportagem (fatos do } \\
\text { aquecimento); } \\
\text { * Infográfico (infográfico } 1 \text { e } \\
\text { infográfico 2); } \\
\text { * Charges; } \\
\text { * imagens ilustrativas da } \\
\text { temática da parte da seção. }\end{array}$ & $\begin{array}{l}\text { *Verbal; } \\
\text { * Visual. }\end{array}$ & $\begin{array}{l}{ }^{*} \text { Escrita; } \\
{ }^{*} \text { Imagem estática } \\
\text { (desenhos, pictogramas, } \\
\text { fotografias e imagens } \\
\text { computadorizadas); } \\
{ }^{*} \text { Imagem em movimento } \\
\text { (imagens } \\
\text { computadorizadas). }\end{array}$ \\
\hline & Atividades Seção 1 - 1 & $\begin{array}{l}\text { 1. Relacionar o conceito de adaptação, da Biologia } \\
\text { evolutiva, ao processo de aquecimento global } \\
\text { motivado pela ação predatória do homem; } \\
\text { 2. Analisar e interpretar uma vídeo-propaganda, } \\
\text { considerando os sietemas semióticos que a } \\
\text { compõem (verbal, visual, músical). }\end{array}$ & $\begin{array}{l}\text { * Questão escolar; } \\
\text { *Glossário; } \\
\text { * Vídeo-propaganda. }\end{array}$ & $\begin{array}{l}\text { *Verbal; } \\
\text { * Visual; } \\
\text { * Musical. }\end{array}$ & $\begin{array}{l}\text { *Escrita; } \\
\text { *Imagem em movimento } \\
\text { (imagens } \\
\text { computadorizadas); } \\
\text { * Música criada por } \\
\text { computador. }\end{array}$ \\
\hline & $\mathrm{CO}=$ = Calor & $\begin{array}{l}\text { 1. Compreender os processos de produção de } \mathrm{CO} 2 \\
\text { e seus impactos no meio ambiente; } \\
\text { 2. Analisar e interpretar um infográfico. }\end{array}$ & $\begin{array}{l}\text { * Texto explicativo (CO2 = } \\
\text { calor); } \\
\text { * Infográfico (infográfico 3). }\end{array}$ & $\begin{array}{l}\text { *Verbal; } \\
\text { * Visual. }\end{array}$ & \begin{tabular}{|l} 
*Escrita; \\
*Imagem estática \\
(imagens \\
computadorizadas, \\
gráficos e diagramas).
\end{tabular} \\
\hline & Mitos do aquecimento & $\begin{array}{l}\text { 1. Compreender o processo de tentativa de } \\
\text { construção de um discurso científico incontestável; } \\
\text { 2. Identificar os recursos utilizados para a tentativa } \\
\text { de construção de um discurso científico } \\
\text { incontestável; } \\
\text { 4. Refletir sobre os interesses que guiam a } \\
\text { construção de um discurso científico incontestável; } \\
\text { 3. Analisar os efeitos de sentido construídos pelas } \\
\text { imagens ilustrativas da parte da seção; } \\
\text { 4. Analisar e interpretar um artigo de divulgação } \\
\text { científica. }\end{array}$ & $\begin{array}{l}\text { * Texto explicativo } \\
\text { (Introdução ao artigo Mitos } \\
\text { do aquecimento); } \\
\text { * Artigo de divulgação } \\
\text { científica (Mitos do } \\
\text { aquecimento); } \\
\text { * Imagens ilustrativas. }\end{array}$ & $\begin{array}{l}\text { *Verbal; } \\
\text { * Visual. }\end{array}$ & \begin{tabular}{|l} 
* Escrita; \\
*Imagem estática \\
(fotografias e imagens \\
computadorizadas); \\
*Imagem em movimento \\
(imagens \\
computadorizadas).
\end{tabular} \\
\hline & Atividades Seção 1 - 2 & $\begin{array}{l}\text { 1. Compreender as origens do CO2 e sua relação } \\
\text { com o aquecimento global; } \\
\text { 2. Analisar um curtametragem animado; } \\
\text { 3. Analisar e interpretar gêneros (texto explicativo, } \\
\text { vídeo-propaganda e diagrama) em sistemas } \\
\text { semióticos distintos (verbal e visual), estabelecendo } \\
\text { relações quanto às suas significações pretendidas; } \\
\text { 4. Analisar e interpretar uma vídeo-propaganda e } \\
\text { uma animação curtametragem, considerando os } \\
\text { sistemas semióticos que a compõem (verbal, visual, } \\
\text { musical). }\end{array}$ & $\begin{array}{l}\text { * Questão escolar; } \\
\text { *Animação } \\
\text { curtametragem(vídeo } 1 \text { das } \\
\text { atividades } 2 \text { da seção1); } \\
\text { *Vídeo-propaganda(vídeo } 2 \\
\text { das atividades } 2 \text { da seção1); } \\
\text { * Diagrama (diagrama eco- } \\
\text { ego). }\end{array}$ & $\begin{array}{l}\text { *Verbal; } \\
\text { *Visual; } \\
\text { * Musical. }\end{array}$ & $\begin{array}{l}\text { *Escrita; } \\
\text { *Imagem estática (imagem } \\
\text { computadorizada); }\end{array}$ \\
\hline
\end{tabular}

Tabela 1: Seção 1 do MDDI. 


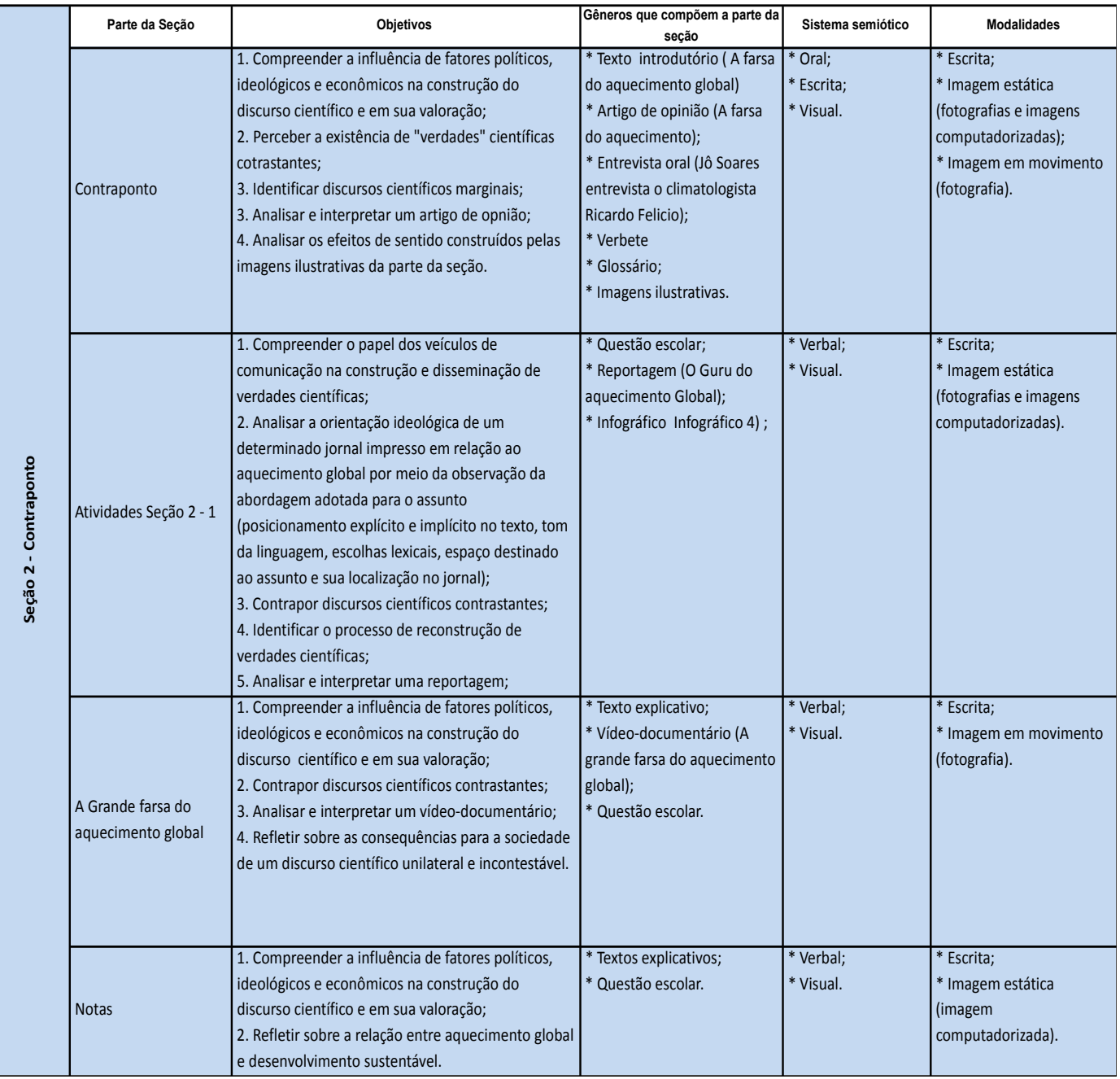

Tabela 2: Seção 2 do MDDI.

\begin{tabular}{|c|c|c|c|c|c|}
\hline \multirow{5}{*}{ 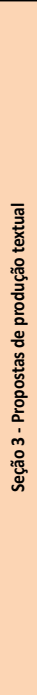 } & Parte da Seção & Objetivos & $\begin{array}{c}\text { Gêneros que compöem a parte da } \\
\text { seçăo }\end{array}$ & Sistema semiótico & Modalidades \\
\hline & A tirania de muitos & $\begin{array}{l}\text { 1. Compreender o conceito de tirania de muitos do } \\
\text { filósofo John Stuart Mill; } \\
\text { 2. Relacionar o conceito à questão do aquecimento } \\
\text { global; } \\
\text { 3. Analisar os efeitos de sentido construídos pelas } \\
\text { imagens ilustrativas da parte da seção. }\end{array}$ & $\begin{array}{l}\text { *Artigo de opinião (A tirania } \\
\text { de muitos); }\end{array}$ & $\begin{array}{l}\text { *Verbal; } \\
\text { * Visual. }\end{array}$ & $\begin{array}{l}\text { *Escrita; } \\
\text { *Imagem estática (imagem } \\
\text { computadorizada); }\end{array}$ \\
\hline & $\begin{array}{l}\text { Proposta de produção } \\
\text { textual } 1\end{array}$ & $\begin{array}{l}\text { 1. Compreender a estrutura, situação de } \\
\text { comunicacional e intenção de comunicação do } \\
\text { gênero dissertação escolar; } \\
\text { 2. Relacionar aquecimento global, o processo de } \\
\text { construção e disseminação de verdades científicas } \\
\text { e o conceito tirania de muitos de John Stuart Mill. } \\
\text { 3. Analisar os efeitos de sentido construídos pelas } \\
\text { imagens ilustrativas da parte da seção. }\end{array}$ & $\begin{array}{l}\text { * Enunciado de proposta de } \\
\text { produção textual; } \\
\text { * Glossário. }\end{array}$ & $\begin{array}{l}\text { *Verbal; } \\
\text { * Visual. }\end{array}$ & $\begin{array}{l}\text { *Escrita; } \\
\text { *Imagem estática (imagem } \\
\text { computadorizada); }\end{array}$ \\
\hline & $\begin{array}{l}\text { Proposta de produção } \\
\text { textual } 2\end{array}$ & $\begin{array}{l}\text { 1. Compreender a estrutura, situação de } \\
\text { comunicacional e intenção de comunicação do } \\
\text { gênero carta do leitor. }\end{array}$ & $\begin{array}{l}\text { *Enunciado de proposta de } \\
\text { produção textual; } \\
\text { * Glossário. }\end{array}$ & ${ }^{*}$ Verbal. & * Escrita. \\
\hline & $\begin{array}{l}\text { Proposta de produção } \\
\text { textual } 3\end{array}$ & $\begin{array}{l}\text { 1. Construir um Tumblr cujo acervo de informações } \\
\text { postadas sutente um ponto de vista específico na } \\
\text { discussão acerca do aquecimento global. }\end{array}$ & $\begin{array}{l}\text { *Enunciado de proposta de } \\
\text { produção textual; } \\
\text { * Glossário. }\end{array}$ & * Verbal. & * Escrita. \\
\hline
\end{tabular}

Tabela 3: Seção 3 do MDDI. 
A análise do MDDI a partir das tabelas descritoras revela a preocupação do material em situar seu trabalho no conceito de multiletramentos, pois é nítida a variedade de gêneros que envolvem múltiplas linguagens e semioses. Além disso, busca-se caracterizar a pluralidade e diversidade cultural mediante os posicionamentos distintos que são elucidados pelas discussões promovidas ao longo das seções. entretanto, nas atividades, nota-se também a tendência a manter um trabalho individualizado, seguindo o padrão já consolidado em livros didáticos. Há também pouca motivação para pesquisas no hipertexto e hipermídia, para curadoria de informações e para trabalho com produção de gêneros multissemióticos, por exemplo. Além disso, as propostas de atividade finais são voltadas para produção de gêneros valorizados por vestibulares (dissertação e carta do leitor), embora haja uma proposta de criação de um Tumblr. Assim, fica evidente a tendência a manter o trabalho limitado a práticas voltadas para um currículo situado em sua maioria no letramento da letra.

O fato de o MDDI em questão ter sido produzido dentro de um sistema institucional que estipula e valoriza práticas de ensino específicas, direcionadas por um currículo fruto dessa lógica, tende a reproduzir nesse material essas mesmas práticas consolidadas. Essa reprodução de lógica estende-se também à prática docente. A despeito disso, é possível afirmar que, em ambos os casos, as tecnologias disponíveis ampliam até certo ponto as possibilidades e introduzem alguns elementos que extrapolam a lógica do currículo tradicional. Entretanto, os limites não podem ser ampliados a ponto de abarcarem plenamente práticas situadas em um novo ethos, pois, nesse caso, haveria uma ruptura com o sistema vigente.

Dependendo dos caminhos de estudo do MDDI escolhidos pelo professor ao longo da aula, o sistema de atividades e seus respectivos sistemas de gênero podem mudar. Entretanto, o protótipo apresenta um conjunto de atividades e, consequentemente, possibilidades de sistemas de gêneros limitados às escolhas de materiais feitas para seu preenchimento. A despeito disso, é possível notar que, se na ocasião de aplicação da pesquisa em questão a conexão à internet estivesse em pleno funcionamento, seria possível ampliar, dentro do conjunto de sistemas de atividades sistematizadas pelo professor, os gêneros que os compõem. Isso ocorreria pois, ao navegar pela internet, os alunos possivelmente se deparariam com infinitas possibilidades de gêneros cujas informações se relacionam à discussão. Assim, notase que, ao inserir na aula a pesquisa em tempo real, por meio do uso de dispositivos 
móveis conectados à internet, as possibilidades de ensino se expandem e os caminhos de condução da discussão de determinado assunto, no caso da disciplina de Produção e Interpretação Textual, tornam-se imprevisíveis e, justamente por isso, ricos em razão das possibilidades de análise, verificação e contraposição de perspectivas distintas proporcionadas por meio dessa estratégia.

\section{RELAÇÃO PROFESSOR-ALUNO DURANTE AS AULAS}

Ao término de seu estudo, Batista (1997) conclui que a organização de textos e exercícios do livro didático delimita a organização da interlocução na instância da aula seja para objetos de ensino relacionados à gramática seja para objetos relacionados à leitura. Diante dessa conclusão, o autor atribui ao professor o papel de alguém que talvez não ensine propriamente, mas alguém que administre e gerencie o ensino. O professor, nesse contexto, não necessitaria, segundo Batista, de um conhecimento acerca do objeto de ensino, "mas do conhecimento sobre o processo de organização de sua prática e sobre as relações dos alunos sobre esses saberes que se ensinam" (BATISTA, 1997, p. 88). Embora não acreditemos que tais constatações possam aplicar-se de forma generalizada às práticas docentes, quer sejam mediadas por materiais digitais ou impressos, ao contrapô-las à análise das aulas mediadas por MDDI registradas para esta pesquisa, percebe-se uma realidade discrepante às conclusões de Batista.

Mediante a análise da experiência em questão, nota-se que, em uma aula mediada por MDDI situado na concepção de protótipo proposta por Rojo (2013), o professor assume um papel protagonista na elaboração do material didático, pois é autor da seleção de textos, mídias e exercícios que preencherão o protótipo. Tal seleção é feita de forma a contemplar os objetivos pedagógicos inicialmente estipulados pelo docente. Além disso, ao ministrar a aula, o professor traça os caminhos de estudo pelo MDDI que podem ser lineares ou não. A escolha pelos caminhos de navegação é feita com base nos objetivos pedagógicos a serem alcançados, as condições tecnológicas disponíveis e o nível de conhecimento da turma para qual se leciona.

Sem padrões estanques delimitados pela organização estrutural de um material didático, os mecanismos de interlocução global para progressão temática em uma aula mediada por MDDI podem ocorrer de diversas formas, segundo as preferências do professor para alcance dos objetivos pedagógicos. No caso da aula registrada, a 
escolha do professor para estruturação da organização global da interlocução se deu por meio da introdução de perguntas, seguidas, não necessariamente de forma linear, pela sistematização, organização e, quando necessário, adequação das respostas dadas pelos alunos de forma a construir uma análise e interpretação de determinado material (texto, imagem ou vídeo) e introduzir um novo tópico. Os tópicos sempre são organizados em torno da interpretação e análise de texto, vídeo ou imagem ou introdução a um deles. Os tópicos introduzidos sempre relacionam-se com os anteriores, de forma a criar progressão na temática da aula. Assim, as conclusões de Batista sobre os mecanismos de progressão "como um conjunto de sequência de atividades relacionadas numa cadeia de discurso que progride temporalmente de tal modo que seus momentos ulteriores contêm parte dos anteriores, acumulados pelo contínuo movimento de recuo e avanço, de síntese e de análise" (BATISTA, 1997, p. 67) aplicam-se à aula em questão.

No caso da organização local e intermediária do discurso, percebem-se o uso de duas estratégias distintas: as sequências triádicas de turno e a organização e/ou complementação das respostas do aluno de forma a construir a informação esperada para progressão da temática e/ou introdução de novo tema.

Nota-se que, por meio dessas estratégias, objetiva-se a construção mútua da análise da questão abordada. Tal constatação contrasta com os dizeres de Batista sobre o objetivo das estratégias locais de organização em seu estudo. Segundo o autor, seu objetivo não está meramente na correção, mas também em "fornecer objetos para que se possa conhecer, avaliar e, assim, corrigir a aprendizagem dos alunos" (BATISTA, 1997, 44). Além disso, ele afirma que o trabalho de transmissão de conteúdos é, assim, não simplesmente uma comunicação, mas uma comunicação que pretende se fazer em substituição ao conhecimento anterior do aluno. $\mathrm{Na}$ aula mediada por MDDI, talvez não em decorrência da mediação pelo material digital, mas pela estratégia adotada pelo professor a fim de alcançar os objetivos pedagógicos estipulados, há o afastamento de uma prática de ensino do caráter corretivo e de substituição de conhecimento e a tentativa de introduzir a mútua construção da análise da temática estudada por alunos e professor.

A construção de polos de interlocução verificada por Batista, em que "o reconhecimento tácito da autoridade do professor, promovido pela estratégia, implica ainda, o reconhecimento tácito da posse, por ele, da dominância da interlocução, e o reconhecimento, também tácito, do papel dominado dos alunos nessa interlocução" 
(BATISTA, 1997, p. 54), ocorre de forma diferente na aula analisada. Em vez da construção de um corpo unificado de alunos centrado pela atenção no professor, notase a constituição dinâmica de polos de interlocução, em que o polo central pode ser ocupado tanto por um aluno quanto pelo professor, embora perceba-se a predominância do professor nesse papel.

\section{CONSIDERAÇÕES FINAIS}

Este estudo objetivou verificar como se estrutura uma aula mediada por material didático digital interativo e as relações entre professor e aluno nesse contexto. Por meio dos resultados obtidos, foi possível concluir que o trabalho com MDDI construído a partir do conceito de protótipo faz com que o professor assuma um papel ativo na seleção de gêneros, escritos e/ou multissemióticos, que constituem o material, na escolha de objetivos pedagógicos a serem alcançados e os caminhos de estudo pelo MDDI ao longo de uma aula. Tais caminhos, escolhidos mediante o contexto de docência, são estruturados por meio de sistemas de atividades, que, por sua vez, estruturam sistemas de gêneros. Dependendo dos caminhos de estudo do MDDI escolhidos pelo professor ao longo da aula, o sistema de atividades e seus respectivos sistemas de gênero podem mudar. Percebe-se que as possibilidades são muitas. Caso se utilize, na aula, estratégias de pesquisa em tempo real por alunos em hipertexto e hipermídia, as possibilidades de gêneros que compõem os sistemas de atividade tornam-se ainda maiores e imprevisíveis.

As interações verificadas em sala de aula ao longo da pesquisa apontam para a condução de uma prática docente em que a construção da análise do objeto de estudo se dá de forma mútua entre professor e alunos. Tal prática, afasta-se de uma educação baseada em métodos corretivos e na mera substituição de conhecimento.

\section{REFERÊNCIAS}

BAHKTIN, M. M. Estética da criação verbal. São Paulo: Martins Fontes, 2003[1952-53/1979]. Tradução de Paulo Bezerra, 4a.ed.

BATISTA, A. Aula de Português: discurso e saberes escolares. São Paulo: Martins Fontes, 1997. 
BAZERMAN, C. Atos de fala, gêneros textuais e sistemas de atividades: como os textos organizam atividades e pessoas In: DIONÍSIO, A.; HOFFNAGEL, J. (orgs., trads.) Gêneros textuais, tipificação e interação. São Paulo: Cortez Editora, 2005, p. $19-46$.

COPE, B.; KALANTZIS, M. (Eds). Multiliteracies - literacy learning and the design of social futures. New York: Routledge, 2006[2000].

DIONÍSIO, A. P.; HOFFNAGEL, J. (orgs. e trads.) Gêneros textuais, tipificação e interação. São Paulo: Cortez Editora, 2005, pp. 19-46.

GEE, J. P. Social linguistics and literacies: ideology in discourses. London: Falmer Press, 1996.

KALANTZIS, M.; COPE, B. Changing the role of schools. In: B. COPE; M. KALANTZIS (Eds.). Multiliteracies - literacy learning and the design of social futures. New York: Routledge, 2006 [2000], p. 121-148.

LANKSHEAR, C.; KNOBEL, M. Sampling "the new" in new literacies. In: (Orgs.) A new literacies sampler: new literacies and digital epistemologies. New York: Peter Lang, 2007. Vol. 29, p. 1-24.

LEMKE J. L. Multimedia and Discourse Analysis. In: J. P. GEE; M. HANDFORD (Eds.). Routledge handbook of discourse analysis. London: Routledge, 2011. p. 263-267.

NEW LONDON GROUP. A pedagogy of multiliteracies: Designing social futures. In: B. COPE; M. KALANTZIS (Eds.). Multiliteracies - literacy learning and the design of social futures. New York: Routledge, 2006[1996], p. 09-37.

ROJO, R. Fazer linguística aplicada em perspectiva sócio-histórica: privação sofrida e leveza de pensamento. In MOITA-LOPES, L.P. da (Org.). Por uma linguística aplicada indisciplinar. São Paulo. Parábola, 2006. P. 258-283.

ROJO, R. Práticas de ensino em língua materna: Interação em sala de aula ou aula como cadeia enunciativa? In: Kleiman, A; Cavalcanti, M. (orgs.) Linguística aplicada - suas faces e interfaces. Campinas, SP: Mercado de Letras, 2007, p. 339360.

ROJO R.Materiais didáticos no ensino de línguas. In: MOITA-LOPES, L. P. da (Org.). Linguística aplicada na modernidade recente - Festschrift para Antonieta Celani. São Paulo, SP: Parábola Editorial/Cultura Inglesa, 2013, p. 163-195. 
SCHNEUWLY, B.; G. S. CORDEIRO \& J. DOLZ "A la recherche de l'objet enseigné: une démarche multifocale”. Mimeo, inédito, 2005.

\section{O AUTOR}

Jezreel Gabriel Lopes é doutorando pela Universidade Estadual de Campinas, em Linguística Aplicada, na área de Linguagem e Educação. Além disso, atua como professor de Produção e Interpretação Textual no Ensino Médio e produtor de materiais didáticos.

E-mail: gabriellopes17@,hotmail.com 